\title{
Notch Signaling in Skeletal Development, Homeostasis and Pathogenesis
}

\author{
Jennifer T. Zieba $®$, Yi-Ting Chen, Brendan H. Lee and Yangjin Bae* \\ Department of Molecular and Human Genetics, Baylor College of Medicine, Houston, TX 77030, USA; \\ Zieba.jennifer@gmail.com (J.T.Z.); Yi-Ting.Chen@bcm.edu (Y.-T.C.); blee@bcm.edu (B.H.L.) \\ * Correspondence: bae@bcm.edu
}

Received: 1 January 2020; Accepted: 13 February 2020; Published: 19 February 2020

check for updates

\begin{abstract}
Skeletal development is a complex process which requires the tight regulation of gene activation and suppression in response to local signaling pathways. Among these pathways, Notch signaling is implicated in governing cell fate determination, proliferation, differentiation and apoptosis of skeletal cells-osteoblasts, osteoclasts, osteocytes and chondrocytes. Moreover, human genetic mutations in Notch components emphasize the critical roles of Notch signaling in skeletal development and homeostasis. In this review, we focus on the physiological roles of Notch signaling in skeletogenesis, postnatal bone and cartilage homeostasis and fracture repair. We also discuss the pathological gain- and loss-of-function of Notch signaling in bone and cartilage, resulting in osteosarcoma and age-related degenerative diseases, such as osteoporosis and osteoarthritis. Understanding the physiological and pathological function of Notch signaling in skeletal tissues using animal models and human genetics will provide new insights into disease pathogenesis and offer novel approaches for the treatment of bone/cartilage diseases.
\end{abstract}

Keywords: skeletogenesis; bone; cartilage; fracture repair; osteoporosis; osteoarthritis; osteosarcoma; bone metastasis

\section{Introduction}

Notch signaling is an evolutionarily well-conserved pathway that regulates critical processes during embryonic development, cell fate determination, proliferation, differentiation, and homeostasis. Since the discovery of mutant flies with notched wings by Dexter and Morgan, there have been numerous studies and animal models that have elucidated the physiological and pathological roles of Notch signaling. Moreover, essential roles of Notch signaling in development have been uncovered through various inherited and somatic conditions caused by mutations in the core and accessory components of the Notch pathways. Notch receptors and their ligands are transmembrane proteins and initiate their signaling cascade by cell-to-cell physical interactions. Humans have four Notch receptors (NOTCH1-4) and five different Notch ligands (JAG1, JAG2, DLL1, DLL3 and DLL4). Upon the interaction of Notch receptors and cognate Notch ligands via direct cell contact, Notch receptors undergo sequential proteolytic cleavages. The extracellular domain of the receptor is cleaved by metalloproteinase tumor necrosis factor-a converting enzyme (TACE) and then further cleaved by a $\gamma$-secretase complex of Presenilin1 and Presenilin2 to become a Notch intracellular domain (NICD). The NICD subsequently translocates to the nucleus and interacts with RBPJK and MAML to activate transcription by displacing the co-repressor complex bound to RBPJK. This transcription complex induces the canonical expression of Hairy Enhancer of Split family genes; HES1, HES3, HES5 and HES7 and HES-related with YRPW motif family genes; HEY1, HEY2 and HEYL. NICD can also interact with proteins other than RBPJK to exert its function, which is termed as the non-canonical, or RBPJK-independent, Notch pathway. 
The role of Notch signaling in skeletal development and homeostasis has been established by studies conducted in both genetically modified animal models and in vitro. Furthermore, a select group of genetic skeletal disorders associated with Notch mutations corroborate the physiological roles of Notch signaling in skeletal tissues.

In this review, we will focus on Notch signaling in bone and cartilage development and maintenance of homeostasis, as well as in the pathological context, such as the joint degenerative disease osteoarthritis $(\mathrm{OA})$ and cancers including primary bone cancer and metastatic cancer.

\section{Notch Signaling in Human Skeletal Diseases}

The critical roles of Notch signaling were highlighted by the discovery of mutations in human genetic diseases that caused defects in development and postnatal homeostasis. Subsequently, delineating the underlying mechanisms of these diseases have illuminated the role of Notch pathways in the skeleton.

Adams Oliver syndrome (AOS), a rare congenital disorder characterized by aplasia cutis congenita and terminal transverse limb defects, is associated with mutations in several Notch pathway components. These genes include NOTCH1, DLL4, and CSL, the human ortholog of RBPJK. Most of the mutations occurring in NOTCH1 reside in the EGF-like repeats of the extracellular domain, causing structural changes that lead to presumably context-dependent NOTCH1 loss-of-function [1]. Heterozygous missense mutations in CSL lead to defects in DNA binding to Notch target genes [2]. Missense and nonsense mutations in DLL4 lead to loss of DLL4 function in AOS [3].

Alagille syndrome is an autosomal dominant disease affecting multisystem organs including the craniofacial skeleton and vertebrae. The failure of the vertebrae to fuse ventrally during development causes a 'butterfly' appearance in radiographic images [4]. Craniofacial developmental abnormalities include craniosynostosis and characteristic facial features, including a broad nasal bridge, deep set eyes, pointed chin, prominent forehead, and triangular facies. Also, patients have short stature, low bone mass and increased fracture incidence. Alagille syndrome is associated with loss-of-function mutations in JAG1, which are found across the extracellular and intracellular domain of the JAG1 protein [5-8]. Also, mutations of NOTCH2, either in isolation or in conjunction with mutations of JAG1, have been reported $[9,10]$. However, null mutations of Jag1 or inactivation of Notch2 in mice result in embryonic lethality, while Jag1 null mice have defective embryonic and yolk sac vasculature and embryonic lethality due to hemorrhage [11]. Interestingly, the combined heterozygous inactivation of Jag1 and a hypomorphic Notch2 allele in mice recapitulated Alagille syndrome [12].

Spondylocostal dysostosis (SCDO) is characterized by vertebral segmentation defects and rib anomalies due to dominant, recessive, and sporadic mutations of genes encoding various components of the Notch signaling pathway [13]. DLL3, MESP2, HES7 and LFNG are all found to harbor causative mutations associated with SCDO [14-17]. Inactivation of Lfng or Hes7 in mice leads to abnormal vertebral columns and rib cage development $[18,19]$. Homozygous missense loss-of-function mutations in LFNG and HES7 are associated with SCDO $[17,20]$.

Hajdu-Cheney syndrome (HCS) is a rare, autosomal, dominantly inherited disease. Patients exhibit prominent skeletal features including facial dysmorphisms and craniofacial defects, such as micrognathia, midface flattening, and dental abnormalities. HSC is caused by heterozygous mutations in NOTCH2 [21,22]. These mutations lead to truncated NOTCH2 protein which becomes stable to ubiquitination degradation. As a consequence, HCS mutations enhance NOTCH2 signaling. Ernesto et al. generated a Notch 2 mutant mouse harboring a truncating mutation in exon 34 upstream of the PEST domain [23]. This mouse model exhibited cancellous and cortical bone osteopenia secondary to increased bone resorption, recapitulating HSC.

Lateral meningocele syndrome (LMS) is a rare disorder characterized by facial anomalies, hypotonia, and meningocele with related neurological dysfunction [24]. Skeletal manifestations include short stature, scoliosis, pectus excavatum, Wormian bones, thick calvariae, increased density of the base of the skull, and increased bone remodeling [25]. The gain-of-function mutation in NOTCH3 
due to the deletion of the PEST domain results in elevated NOTCH3 signaling. The inheritance pattern of LMS is not yet clear. However, most documented cases reveal de novo heterozygous truncating mutations in exon 33 of NOTCH3 [26].

In summary, the Notch pathway regulates a vast array of essential developmental processes in skeletogenesis. Not surprisingly, mutations in genes encoding the Notch pathway exhibit severe deformities and disorders as described above in Table 1. Furthermore, the fine tuning of Notch signaling can be regulated by post-translational modifications such as glycosylation and fucosylation [27]. The discovery of these genetic modifiers may help to understand the severity of these disorders. The variable expressivity in Alagille syndrome may be partially explained by these modifiers. Therefore, ongoing efforts to find human mutations by whole genome sequencing and analysis, as well as the global sharing of genomic and phenotypic data, may improve the understanding Notch-associated genetic diseases by identifying unique structure-function correlations informed by genotype as well as potentially oligogenic inheritance that is informed by strong modifier alleles.

Table 1. Human genetic diseases associated with mutations in Notch signaling.

\begin{tabular}{|c|c|c|c|}
\hline Disease & Mutation & Notch Effect & Symptoms \\
\hline $\begin{array}{l}\text { Adams Oliver } \\
\text { Syndrome }\end{array}$ & $\begin{array}{l}\text { NOTCH1 } \\
\text { DLL4 } \\
\text { RBPJK }\end{array}$ & $\begin{array}{l}\text { Loss of } \\
\text { function }\end{array}$ & $\begin{array}{l}\text { Underdeveloped skull and absent or scarred skin } \\
\text { (Aplasia cutis congenital), mild to severe limb defect } \\
\text { (Terminal transverse limb defects), cardiovascular } \\
\text { malformations/dysfunctions, brain anomalies, and less } \\
\text { frequent renal, liver and eye anomalies }\end{array}$ \\
\hline $\begin{array}{l}\text { Alagille } \\
\text { Syndrome }\end{array}$ & $\begin{array}{l}J A G 1 \\
\mathrm{NOTCH} 2\end{array}$ & $\begin{array}{l}\text { Loss of } \\
\text { function }\end{array}$ & $\begin{array}{l}\text { Multisystem disorder with a wide spectrum of clinical } \\
\text { variability; bile duct paucity, cholestasis, cardiac defect, } \\
\text { butterfly vertebrae, craniosynostosis and characteristic } \\
\text { facial features, low bone mass and increased } \\
\text { fracture incidence }\end{array}$ \\
\hline $\begin{array}{l}\text { Spondylocostal } \\
\text { Dysostosis }\end{array}$ & $\begin{array}{c}\text { DLL3 } \\
\text { MESP2 } \\
\text { HES7 } \\
\text { LFNG }\end{array}$ & $\begin{array}{l}\text { Loss of } \\
\text { function }\end{array}$ & Vertebral segmentation defects, rib abnormalities \\
\hline $\begin{array}{l}\text { Hajdu-Cheney } \\
\text { Syndrome }\end{array}$ & NOTCH2 & $\begin{array}{l}\text { Gain of } \\
\text { function }\end{array}$ & $\begin{array}{l}\text { Short stature, coarse and dysmorphic facies, bowing of } \\
\text { long bones, and vertebral anomalies; focal bone } \\
\text { destruction (acroosteolysis) and osteoporosis }\end{array}$ \\
\hline $\begin{array}{l}\text { Lateral } \\
\text { Meningocele } \\
\text { Syndrome }\end{array}$ & $\mathrm{NOTCH} 3$ & $\begin{array}{l}\text { Gain of } \\
\text { function }\end{array}$ & $\begin{array}{l}\text { Facial anomalies, hypotonia, meningocele, short stature, } \\
\text { scoliosis, Wormian bones, and thick calvariae }\end{array}$ \\
\hline
\end{tabular}

\section{Notch Signaling in Chondrogenesis}

Appendicular skeletal development begins with a cartilage intermediate formed from the condensation of mesenchymal chondrocyte progenitors. This condensation is surrounded by a thin layer of spindle-shaped cells that will eventually form the perichondrium. Following initial condensation and proliferation, chondro-progenitors differentiate and become resting chondrocytes, after which cells undergo proliferation and develop a hypertrophic phenotype, inducing mineralization in the ECM, and finally undergoing programmed cell death. For long bones, these phases of chondrocyte proliferation and differentiation comprise a growth plate in an overall process known as endochondral bone formation. Endochondral bone formation is accomplished through the tight regulation of gene expression and multiple signaling pathways, such as TGF $\beta$, WNT, FGF, IHH, and NOTCH. The temporal-spatial regulation of these signaling pathways determines the proper chondrocyte maturation [28-31].

The endogenous expression of Notch signaling components within the early mouse limb bud and growth plate have been well characterized. Notch1 is expressed in regions of condensed mesenchymal cells in E12.5 embryos [32]. More specifically, Dong et al. demonstrated the spatial-temporal expression of Notch1 throughout the limb bud mesenchyme at E11.5-12.0 and observed high levels of Notch1 
surrounding the vascular tissue [33]. Notch2 was expressed ubiquitously throughout the limb bud. Expression of downstream targets of Notch signaling such as Hes1 and Hey1 were found closely localized with Notch 2 at the same embryonic stage. The expression profile of ligands Jag1, Dll1, and Dll4 varied. Jag1 was moderately expressed throughout the limb bud mesenchyme but was mainly in the distal medial mesenchyme. Dll1 was expressed throughout the limb bud mesenchyme, and Dll4 expression was restricted to vascular structures.

In differentiating ATDC5 cells (a murine chondrocyte cell line), Watanabe et al. demonstrated early Notch1 expression with Dll1 expression followed shortly thereafter [32]. As chondrocytes matured, Notch1 and Dll1 expression decreased [34]. The expression of Notch receptors and targets become attenuated and mainly restricted at the periphery of the cartilage condensations as chondrocytes mature [32,33]. A reduction in Notch1 expression in human mesenchymal stem cells (MSCs) was also observed as chondrogenic differentiation progressed [35]. Subsequently, Notch1 expression increased in the prehypertrophic and hypertrophic zones of E16.5 through E18.5 limb buds [32,36]. During postnatal long bone maturation, Crowe et al. demonstrated Notch 2 expression was observed throughout the growth plate whereas Delta-1 expression was localized to hypertrophic chondrocytes of P8 through P10 mice [37]. Ligands Serrate1, Serrate2, and Notch1 were not detected in growth plate chondrocytes at these time points. These collective studies demonstrated dynamic expression patterns of Notch signaling components and activation, which support diverse functions throughout chondrocyte maturation and long bone formation.

Studies involving the overexpression of Notch1-NICD (NICD1) demonstrated that while Notch signaling is important for mesenchymal cell proliferation, it also represses chondrogenic differentiation. Watanabe et al. demonstrated that overexpression of NICD1 in ATDC5 cells suppressed chondrogenic differentiation by repressing expression of Col2a1, Agn as well as Sox9. Hes1 overexpression in ATDC5 cells suppressed chondrocyte differentiation markers, although less effectively, indicating that additional Notch targets are involved. Furthermore, exposure of $\gamma$-secretase inhibitor to ex vivo limb bud cultures accelerated initiation of chondrogenic condensation [34], suggesting the negative role of Notch signaling during chondrogenic differentiation. NICD1 overexpression in committed chondrocytes using Col2a1-Cre mice resulted in decreased proliferation of chondrocyte precursors and inhibition of sclerotome differentiation [36]. Other study demonstrated that Hey1 and Hes1 blocks Sox9 binding to the promoter region of Col2a1, thereby repressing Col2a1 expression during chondrogenesis in human MSCs [35]. These studies demonstrate that Notch signaling plays a dual role in maintaining the proliferation of progenitor cells while also suppressing chondrogenic differentiation.

Subsequent studies revealed the repressive role of Notch downstream targets in chondrocyte differentiation. Dong et al. showed that Hes1 suppresses chondrogenesis in ex vivo limb bud cultures while Hey1 and HeyL are dispensable [33]. Rutkowski et al. further reported that both in vitro and in vivo, Hes1 expression follows but does not affect Sox9 expression changes during chondrogenesis [38]. However, Hes5 had an inverse relationship with Sox9 expression and was recruited to upstream promoter regions of $S_{0 x}$, suggesting that Hes5 is a negative regulator for Sox 9 transcription. Consistent with these studies, chondrogenesis was accelerated in mouse limb buds when Hes1 and Hes5 were deleted in limb mesenchymal cells using Prx1-Cre mice [38,39]. Tian et al. added to the growing list of Notch targets that affect chondrogenesis by showing NICD binds to the Twist1 promoter region [40]. The inhibition effect of Notch on chondrogenesis was reduced with knockdown of Twist1 in limb bud cultures.

Notch signaling also plays critical roles during chondrocyte maturation. Crowe et al. demonstrated the function of Notch in chondrocyte hypertrophy in 1999 [37]. In chick limb buds, Delta1 mis-expression blocks chondrocyte maturation and reduces levels of ossification. The removal of $\gamma$-secretase (Presenilin1 and Presenilin2), as well as the deletion of Notch1 and Notch2 in Prx1-Cre mice, resulted in the accumulation of hypertrophic chondrocytes in the growth plate during embryonic development [41]. Also, the single conditional deletion of Notch2 but not Notch1 recapitulated the $\gamma$-secretase removal, indicating a more predominant role for Notch2 in growth plate chondrocyte hypertrophy [41,42]. 
Interestingly, Mead et al. also demonstrated an increased hypertrophic zone with the overexpression of NICD1 in committed chondrocytes using Col2a1-Cre mice along with reduced Sox9 expression [36]. Sox 9 was expressed in the proliferating zone but not in the hypertrophic zone of chondrocytes [43]. Mechanistically, it has been demonstrated that Sox9 expression during chondrocyte hypertrophy is governed by Rbpjk. When Rbpjk is deleted in Prx1-Cre mice, Sox9 expression is increased in prehypertrophic chondrocytes, indicating that Notch plays a suppressive role in Sox9 expression. Furthermore, cartilage-specific NICD1 gain-of-function mice displayed a chondrodysplasia phenotype with suppression of Sox9 expression [44]. The removal of Rbpjk from this mutant mouse model rescued the limb defect but "butterfly" vertebrae persisted, suggesting that the removal of Rbpjk did not fully rescue axial skeleton deformity. Also, the Sox9 level was recovered upon the deletion of Rbpjk. Moreover, chromatin immunoprecipitation (ChiP) assays demonstrated the recruitment of Rbpjk/NICD complex to the upstream regulatory region of the Sox9 gene, indicating a Rbpjk-dependent (Notch canonical) mechanism [44]. This study also suggested that Rbpjk-independent Notch signaling (Notch non-canonical) contributes to vertebrae development.

The function of Notch in chondrogenesis is further complicated by its ability to utilize both Rbpjk-dependent and Rbpjk-independent mechanisms, as described above. In Rbpjk-independent Notch signaling, NICD has been shown to interact with members of the BMP, TGF $\beta$, Wnt, and NF-kb protein families, affecting various aspects of signaling [45-53]. Kohn et al. demonstrated that while canonical Notch signaling is important in chondrocyte proliferation and its activity decreases as chondrocytes mature, non-canonical Notch signaling from the perichondrium most likely influences growth plate chondrocyte proliferation, hypertrophy, columnar organization, and cartilage matrix turnover [54]. During limb development, Notch signaling from the perichondrium functions to limit chondrocyte proliferation and differentiation and to direct the growth of the developing limb [55]. The study identified non-canonical Notch signaling as a key regulator of perichondral bone formation using Col2a1-Cre mice driven NICD gain-of-function and Rbpjk deficiency. In this mouse model, it showed enhanced perichondral bone formation as well as changes in growth plate chondrocyte morphology. Furthermore, growth plate chondrocytes showed decreased Ptc1 expression (a target of IHH signaling) whereas perichondral cells exhibited increased Ptc1 expression suggesting that IHH signaling may be the link between Notch and perichondral/chondrocyte cell communication [54].

In chondrogenesis and chondrocyte differentiation, Notch signaling functions in a context-dependent manner. Although it promotes mesenchymal cell proliferation, Notch is generally a suppressor of chondrogenesis (Figure 1a). Notch signaling is typically highly expressed during early chondrogenesis and decreases as chondrocytes differentiate. As chondrocytes prepare to enter hypertrophy, Notch again plays a role as an enhancer of chondrocyte hypertrophy through the regulation of Sox9 expression (Figure 1b). The underlying Notch-mediated Sox9 transcriptional regulation has been uncovered by multiple studies mentioned above. However, Notch targets beyond Sox 9 and the role of Rbpjk-independent Notch signaling during cartilage development remain to be determined. 


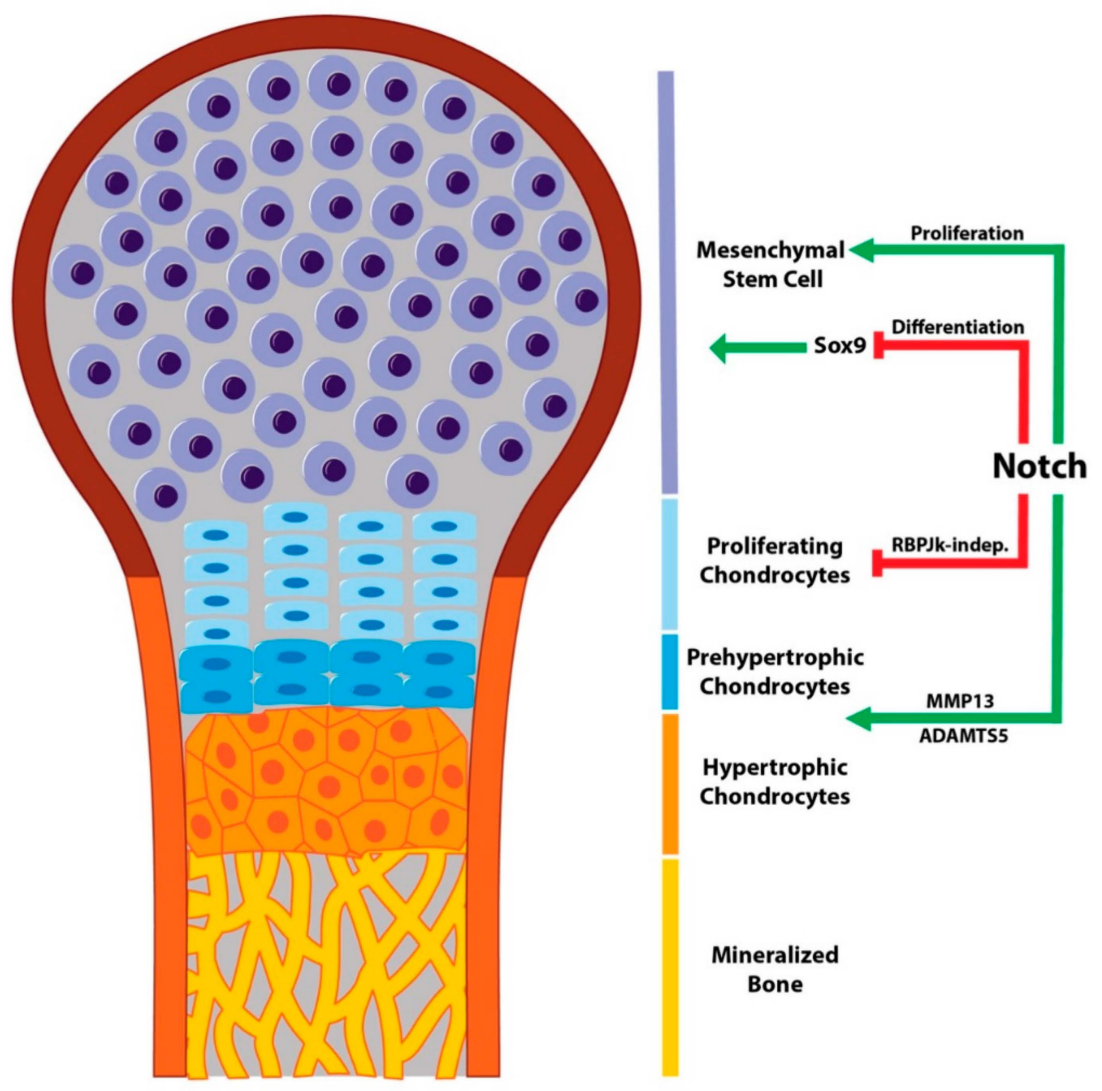

(a)

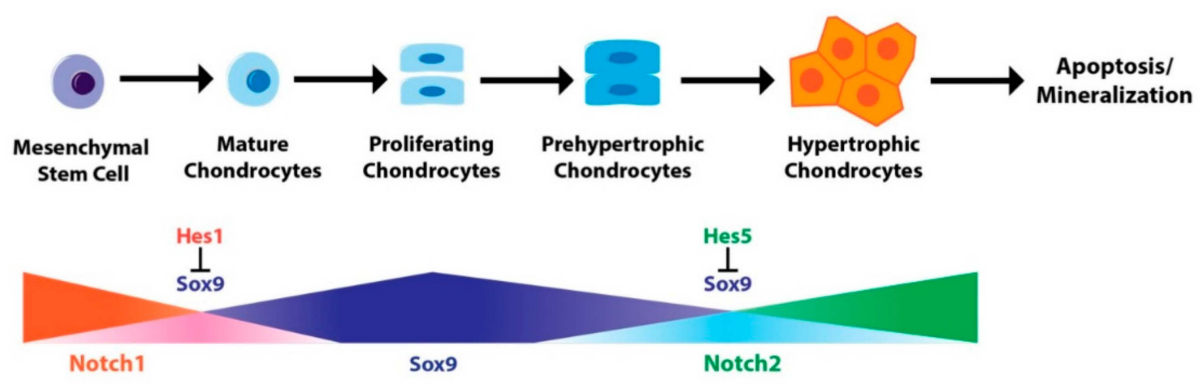

(b)

Figure 1. Notch signaling in chondrogenesis. (a) Notch signaling in growth plate development. Notch signaling maintains the mesenchymal cell population and functions to inhibit chondrogenesis through the reduction in Sox 9 as well as Col2a1 and Agn transcription. As chondrocytes mature, Notch signaling promotes hypertrophy by blocking Sox9 expression while also promoting matrix catabolism through the induction of ADAMTS and MMP13 expression. Notch signaling also regulates chondrocyte proliferation and growth plate organization in a non-cell autonomous manner through its expression in the developing perichondrium. This regulation has been shown to occur independently of RBPjk; (b) Notch signaling in chondrocyte maturation. Notch1 expression is highest in mesenchymal progenitors and prevents chondrocyte maturation by inducing Hes1 expression that in turn blocks Sox 9 and Col2 transcription. Sox9 levels increase as chondrocytes mature and proliferate during growth plate maturation. This increase is then reduced by Notch2 and Hes5, allowing proliferating chondrocytes to undergo hypertrophy and eventually mineralization. 


\section{Notch Signaling and Osteoarthritis}

Osteoarthritis (OA), the most common degenerative joint disorder, is characterized by fibrosis, inflammation, loss of joint cartilage, and variable degrees of synovial tissue dysplasia [56]. As OA progresses, articular chondrocytes proliferate and acquire chondrocyte hypertrophy [57,58]. Many risk factors contribute to the development and progression of $\mathrm{OA}$, including aging, obesity, traumatic injury, and genetics [59]. However, the etiology of OA is still poorly understood. Multiple studies using animal models have demonstrated that Notch signaling is one of the critical regulators in cartilage homeostasis and joint maintenance.

Notch signaling components are expressed in adult articular cartilage, and the majority of chondrocytes residing in articular cartilage express Notch1 [60,61]. Expression levels of NOTCH1, JAG1, and downstream target HES5 are low in differentiated chondrocytes. Interestingly, these genes were abundantly detected in OA biopsies [62]. In post-traumatic OA, the Notch pathway is highly activated in both human and mouse joint tissues [62]. Furthermore, when Notch signaling was blocked by the chemical inhibitor, DAPT, the proliferation of OA chondrocytes was significantly decreased.

In vivo mouse models of NICD1 overexpression within postnatal joint cartilage demonstrate the dual roles of Notch signaling in joint maintenance and OA progression [63]. Sustained Notch activation in joint cartilage leads to an early and progressive OA-like pathology. However, transient Notch activation resulted in enhancing the synthesis of cartilage matrix and promoted joint maintenance [63]. In this study, they showed that the pathological gain in Notch signaling led to increased IL6 and STAT3 as well as MAPK signaling, which contributed to joint cartilage degradation and fibrosis. In addition, several additional signaling pathways, such as the tyrosine kinase signaling, GPCR signaling, and NO signaling pathways, were markedly increased with sustained NICD1 expression in chondrocytes. Therefore, a fine temporal-spatial balance of Notch signaling activity is required to maintain articular cartilage homeostasis and joint integrity. Loss or reduction in cartilage-specific Notch signaling is capable of reducing the abundance of MMP13 (cartilage related protease) within murine joints, as well as delaying cartilage degeneration over the short term [64]. However, the long-term reduction in Notch signaling disrupts the normal homeostasis of the cartilage and ultimately resulted in cartilage degeneration [65]. Overall, these studies showed that Notch signaling plays a complex role in cartilage homeostasis and that transient or physiological Notch signaling in chondrocytes favors a balanced anabolic and catabolic response, whereas sustained or enhanced Notch activity elicits a pathological response through the simultaneous suppression of chondrogenic genes and the induction of genes encoding catabolic factors.

Furthermore, the deletion of Rbpjk in mesenchymal progenitor cells using Prx1-Cre showed a delay in the formation of secondary ossification centers, characterized by persistent hypertrophic cartilage in the epiphyseal region with normal articular cartilage development [65]. Interestingly, these mice later exhibited an early, progressive OA-like pathology with disruption of joint cartilage architecture and ECM composition [65]. Furthermore, to understand the contribution of postnatal chondrocytes to joint cartilage maintenance, Rbpjk was deleted in chondrocytes by Col2a1-Cre. The postnatal deletion of Rbpjk indeed led to age-related progressive OA development, including articular cartilage degradation, mineralization of joint cartilage and altered subchondral bone. The inhibition of Notch signaling in this study further showed altered gene expression of Col2a1, Prg4 (Proteoglycan 4), Col10a1, MMP13 (Metalloproteinase 13) and ADAMTS [65]. Overall, this study demonstrated that the Rbpjk-dependent Notch pathway is required for the joint maintenance and articular cartilage homeostasis. Hes1, a downstream target of Notch signaling, also modulates OA pathogenesis. The genetic deletion of Hes1 in postnatal articular cartilage led to delayed OA development. Mechanistically, Hes1 induces the transcriptional activation of catabolic enzymes such as MMP13 and ADAMTS5 by directly binding to their regulatory regions [64]. Additionally, unbiased microarray assays and ChiP-seq revealed IL6 and ILIrl1 as downstream targets, which are implicated in inflammation. Hes1 functions generally as a transcriptional repressor downstream of Notch signaling; however, it switches to an activator by 
forming a complex with CaMK2 (Ser/Thr protein kinase). This study suggested a new therapeutic potential for OA by modulating the phosphorylation of CaMK2.

Overall, these studies suggest that the role of Notch signaling in joint physiology is highly complex, as well as dose- and context-dependent. A physiological level of Notch activation is required for joint development and articular cartilage maintenance. However, the loss or sustained activation of Notch signaling leads to progressive OA development. This biphasic mode of Notch signaling in joints indeed requires fine tuning and depends on temporal-spatial context.

\section{Notch Regulation of Osteoblast Differentiation and Osteocyte Function}

Skeletal homeostasis is maintained by two distinct mechanisms: bone formation and resorption. While bone formation is driven by the differentiation of chondrocytes to cartilage and subsequent bone mineralization by osteoblasts (bone forming cells), bone resorption is a coordinated effort between osteoblast and osteoclast (bone resorbing cell) activities that remove old bone and maintain mineral metabolism. Imbalance between bone formation and resorption can cause pathological outcomes, such as osteosclerosis, osteopetrosis, or osteoporosis.

Notch signaling plays essential roles in maintaining postnatal bone homeostasis and osteoblast cell fate decisions. Initial in vitro studies of Notch in osteogenesis reflected its conflicting role in osteoblast differentiation. In genetic mouse models of Notch gain-of-function and loss-of-function at specific stages of the osteoblast lineage, Notch signaling functions via a cell-context/stage dependent manner. The overexpression of Notch1 in osteoblast precursors, driven by the Col1a1-3.6kb promoter, repressed osteoblast differentiation and induced severe osteopenia [66,67]. Recent studies further demonstrated the contribution of Notch ligand Jag1 to the regulation of the osteoprogenitor pool. Hence, the deletion of Jag1 in early mesenchymal progenitor cells using Prx1-Cre expanded mature osteoblasts and increased bone mass [68]. In contrast to these findings, the overexpression of Notch ligand Dll1 or the intracellular domain of Notch1 (NICD1) under the control of Col1a1-2.3kb promoter in committed osteoblasts resulted in a severe osteosclerotic phenotype due to the inhibition of osteoblast terminal differentiation, leading to accumulated immature osteoblasts $[69,70]$. These studies suggest that during the early stage of osteoblastogenesis, Notch signaling induces the self-renewal ability of mesenchymal/osteoblastic progenitor cells and suppresses their terminal differentiation to mature osteoblasts. Mechanistically, the Notch-mediated expansion of immature osteoblasts is, in part, due to the inhibition of Wnt/ $\beta$-catenin signaling by NICD1 and the suppression of Runx2 transactivation on osteocalcin (Ocn) [70]. The upregulation of Osterix, along with Cyclin D and Cyclin E, due to NICD expression in committed osteoblasts also leads to the expansion of immature osteoblasts [70]. Moreover, the Notch target Hey1 mediates the inhibition of Nfatc1, a mediator of Notch function in osteoblasts, to suppress osteoblastogenesis accounting for the inhibition of osteoblast differentiation [42].

The loss of function of Notch signaling in committed osteoblasts by deletion of $\gamma$-secretase Presenilin 1 and Presenilin 2 using Col1a1 2.3kb-Cre mice showed an age-related osteoporosis due to elevated osteoclastogenesis [70]. Interestingly, when Presenilin1 and Presenilin2 were deleted in early progenitors by Prx1-Cre (PPS mice), these mice had a high bone mass phenotype at 2 months of age. A similar high bone mass phenotype was observed when Notch1 and Notch 2 were deleted by Prx1-Cre (PNN mice) [41]. PPS and PNN mice exhibited significant bone loss with aging due to an increase in bone resorption and reduction in osteoblast numbers [41]. Moreover, the deletion of Rbpjk in mesenchymal progenitors resulted in a high bone mass seen in PNN and PSS mice, suggesting that canonical Notch signaling is dominant in regulating early osteoblast progenitors and osteoblast-osteoclast coupling [42].

The activation of Notch signaling in osteocytes, terminally differentiated osteoblasts, was performed by overexpressing NICD1 using late osteoblast/osteocyte-specific Dmp1-Cre. These mice showed higher cancellous bone caused by increased bone formation and reduced bone resorption [71]. Mechanistically, the expression of Osteoprotegerin (OPG) was increased with a decrease in Sclerostin level, which led to the inhibition of bone resorption and enhanced Wnt signaling leading to high bone 
mass. This study indicates that Notch signaling contributes to the non-cell-autonomous function of osteocytes in the regulation of osteoclasts. Consistent with these findings, the selective deletion of Rbpjk under conditions of NICD1 activation, driven by Dmp1 promoter, reversed the high bone mass phenotype [72]. These data further showed that Notch canonical signaling in osteocytes regulates osteoclast differentiation and causes osteosclerosis.

In summary, these studies conducted in conditional Notch gain/loss-of-function mouse models demonstrate two manners of regulation in osteogenesis-Notch activation during early osteogenesis sustains mesenchymal and osteoblastic progenitors by promoting proliferation, while repressing differentiation of mesenchymal cells/immature osteoblasts to terminally differentiated osteoblasts (Figure 2). Notch activation in committed osteoblasts leads to osteosclerosis by increased immature osteoblasts due to inhibition of terminal differentiation of osteoblast. When Notch signaling is activated in osteocytes, it shows high bone mass due to reducing bone resorption (Figure 2) [70,73-77].

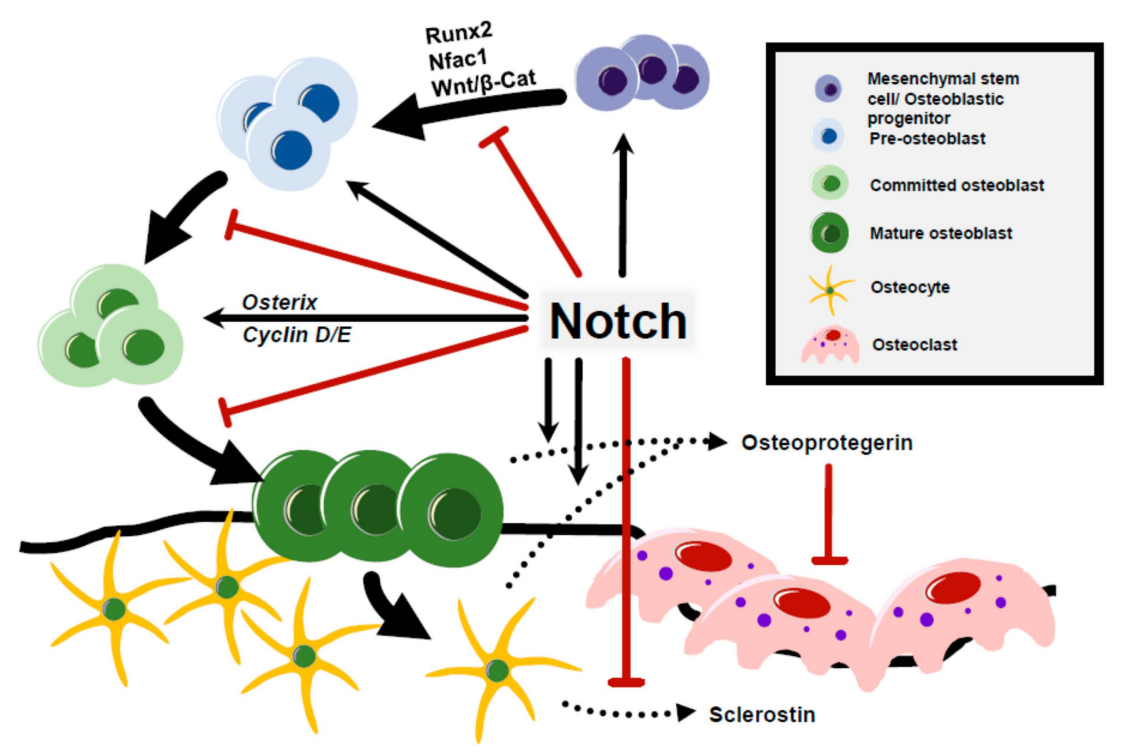

Figure 2. Notch regulation of osteoblast differentiation and osteocyte function. Notch maintains the mesenchymal stem cell (MSC) pool by the repression of Runx2 transactivation on Osteocalcin and suppresses osteoblast differentiation by the Nfatc1-mediated inhibition of Wnt/ $\beta$-catenin signaling. Expression of Notch increases the immature osteoblast pool by upregulating transcription of Osterix, Cyclin D, and Cyclin E. Notch signaling regulates bone resorption in a non-cell-autonomous manner through Osteoprotegerin expression by osteoblasts and osteocytes. Additionally, Notch activation in osteocytes suppresses sclerostin, which enhances Wnt signaling and inhibits bone resorption.

Recent studies have shown several interesting mechanistic aspects of Notch function in modulating osteoblast differentiation. Notch signaling may lead to the suppression of glucose metabolism restricting osteoblast differentiation in mesenchymal progenitors [78]. Another study showed a functional link between Notch signaling and mechanotransduction in which Notch serves as a mediator in response to mechanical strain in mesenchymal cells [79]. Future work on elucidating other components in the Notch pathway, glucose metabolism, and mechanical force associated with osteogenesis and bone homeostasis will be important in understanding the broad effects of Notch on skeletogenesis.

\section{Notch Signaling in Osteoclastogenesis and Bone Resorption}

Osteoclasts are bone resorbing cells derived from differentiated monocytes and macrophages originating from the hematopoietic lineage. M-CSF (macrophage colony-stimulating factor) is essential for the proliferation and survival of osteoclast progenitors, whereas osteoclast differentiation is modulated by RANKL (receptor activator of nuclear factor-kB ligand) binding to RANK to stimulate osteoclast differentiation. OPG, a decoy receptor of RANK, binds to RANKL and inhibits 
osteoclastogenesis [80]. Therefore, the ratio of RANKL/OPG governs osteoclast differentiation. Following differentiation, the osteoclast begins to express TRAP, undergoes multinucleation, and begins bone-resorbing activity. Notch signaling has been shown to be a critical regulator of both osteoclastogenesis and bone resorption.

In vitro, Sekine et al. used immobilized Notch ligand Delta-1 to demonstrate the enhancement of osteoclastogenesis through Notch2/Delta-1 activation [81]. In this study, however, it was shown that the activation of Notch1/ Jag1 inhibited osteoclast differentiation. Nevertheless, inactivation of Notch signaling through $\gamma$-secretase inhibitor resulted in decreased osteoclastogenesis implying that Notch's positive role in osteoclastogenesis is more dominant. On the contrary, another study using immobilized Delta-1 to activate Notch signaling in stromal cells showed an increase in both RANKL and OPG expression, as well as inhibition of M-CSF gene expression, resulting in reduced osteoclast differentiation [82]. Furthermore, knockdown of Notch2 expression in RAW 264.7 cells (a murine pre-osteoclast cell line) resulted in the inhibition of RANKL-induced osteoclast formation, whereas knockdown of Notch1 had no effect in this model [83]. The deletion of Notch1, Notch2, and Notch3 receptors in mouse bone marrow macrophages increased osteoclastogenesis as well as osteoclast precursor proliferation [84]. Specifically, the loss of Notch1 and Notch3 enhanced osteoclastogenesis, whereas Notch2 had no effect. Collectively, these studies indicate that the role of Notch signaling in osteoclast differentiation differs based on the specific ligand/receptor interaction. Ashley et al. demonstrated that that stimulation of Notch signaling in committed osteoclast precursors increased Notch multinucleation and resorptive activity, whereas stimulation prior to precursor osteoclast induction resulted in decreased osteoclastogenesis, demonstrating the distinctive roles of Notch based on differentiation stage [85]. Osteoclastogenesis can also be induced during inflammation by TNF and further enhanced by deletion of Rbpjk in osteoclast precursors [86]. The study also demonstrated that deletion of Rbpjk allows TNF to induce osteoclast formation independently of RANKL. This study showed the cell-autonomous role of Notch signaling in inflammatory osteoclastogenesis.

Osteoclastogenesis can also be induced in a non-cell autonomous manner through the osteoblast lineage production of RANKL and OPG. Notch signaling has a critical role in osteoblastogenesis, as discussed earlier in this review, and this role affects osteoclast formation and function as well. As was observed in PPS and PNN mouse models, their osteoporotic phenotype was due to elevated osteoclast function by increased RANKL and decreased OPG production by osteoblasts [41,70].

Overexpression of Hes1 driven by a Col1a1 2.3kb promoter resulted in enhanced resorptive activity of cultured osteoclast precursors in an osteoblast-splenocyte co-culture assay [87]. This result was further supported by recent mouse models of Hajdu-Cheney syndrome demonstrating that sustained Notch 2 activation in osteoblasts results in increased osteoclastogenesis as well as osteoclast resorptive activity $[23,88]$.

Overall, Notch activity in various stages of osteoclast differentiation is governed by specific ligand-receptor interactions through both cell-autonomous and non-cell-autonomous mechanisms. Additional studies concerning the role of receptor-ligand combination in cell types at multiple stages of differentiation would help to clarify Notch's role in osteoclasts and aid in identifying additional targets to restore bone loss. Further, whether non-canonical Notch signaling plays a role in osteoclastogenesis and osteoclast function has yet to be determined.

\section{Notch Function in Skeletal Stem Cells and Fracture Healing}

The healing of bone fractures involves a complex series of events involving multiple tissues and signaling pathways. The process of healing consists of an initial immune response, the recruitment of progenitor cells from the bone marrow and periosteum followed by the formation of an enlarged soft callus stabilizing the injury. This cartilage intermediate then undergoes a process similar to endochondral ossification where it is replaced with woven bone that is eventually resorbed, replaced with lamellar bone, restoring the bone's original shape. Many pathways involved in endochondral ossification also play critical roles in fracture healing, including Notch signaling. Generally, Notch 
signaling is upregulated upon bone injury, with Jag1 and Notch2 being the most highly expressed in the mesenchymal cell population and decreased during chondrogenesis [89]. In this study, it was shown that Jag2, Notch4, and Hes1 had the greatest change in callus tissue gene expression, with the highest expression at 10 days post-fracture. So, while there are certain components of Notch signaling that are specifically expressed during early progenitor cell recruitment in fracture healing, there are others that are expressed throughout the healing process.

The role of Notch signaling in fracture healing has been elucidated by mouse tibial/femoral fracture models and can be divided into two groups: genetic models and treatment models. An inducible transgenic mouse model of $M x 1-C r e ; d n M A M L$, which impairs canonical Notch signaling by dominant negative MAML in skeletal stem cells, reduced cartilage formation in the callus due to prolonged inflammatory cytokine expression at 10 days post-fracture. These mice also showed an increased callus to bone proportion with no change in callus size along with an increase in osteoclast density but decreased osteoblast differentiation, which indicates an altered bone remodeling [90]. Targeted deletion of Rbpjk by Prx1-Cre, however, showed prominent intramembranous bone formation extending from the periosteum, but the fracture persisted in non-union. Interestingly, fracture healing was normal in animals harboring loss of Rbpjk in committed chondrocytes and mature osteoblasts [91]. In contrast, the activation of Notch signaling in $\alpha$ SMA-expressing periosteal cells inhibited their osteogenic differentiation and ability to induce ectopic bone formation [92]. These genetic mouse studies demonstrated that Notch signaling mainly compromises cell differentiation but does not affect cell proliferation during fracture repair. Clearly, Notch signaling plays critical roles during fracture repair based on healing stages as well as specific cell subpopulation.

Treatment models have also elucidated the roles of Notch in fracture healing. By treating a fracture model with an intermittent $\gamma$-secretase inhibitor, Wang et al. showed prominent cartilage and bone callus formation and superior strength compared to untreated fractures due to the promotion of mesenchymal cells differentiation [91]. Furthermore, this transient inhibition of Notch signaling also resulted in an increased osteoclastogenesis during fracture remodeling, which likely occurs in a non-cell autonomous fashion. Overall, transient Notch inhibition accelerated fracture repair. However, mesenchymal cell sheet cultures with Notch activation and allografted to fractured tissue showed enhanced callus formation by increasing osteogenic potential as well as decreasing cellular senescence [93]. The delivery of Jag1 has also been shown to enhance femoral defect healing through increased bone formation [94]. These studies reveal Notch's ability to regulate progenitor cell differentiation in fracture healing but also reveal its opposing roles based on specific cell types as well as its signaling activation or inhibition source.

Notch signaling has important roles in angiogenesis in several tissues but more specifically during bone development. In long bone development, Notch signaling promotes endothelial cell proliferation as well as sprouting angiogenesis through its regulation of VEGF and Noggin expression [95,96]. Similar to endochondral ossification event, vascularization of the fracture callus is critical to mobilize osteoblast precursors and other progenitor cells to the fractured region. Pharmacological inhibition of angiogenesis has been shown to impair fracture healing through callus reduction [97]. Although there are no specific studies linking Notch and angiogenesis in fracture healing, it is likely that Notch plays a critical role in regulating the blood vessels invasion of the developing callus.

Overall, Notch appears to function as a suppressor of the initial inflammatory response. Meanwhile, in skeletal progenitor cells, Notch functions as a suppressor of intramembranous bone formation, but an inducer of progenitor cell commitment. Finally, in periosteal cells, Notch functions as an inhibitor of osteogenesis. Notch receptor/ligand combinations and their nuclear targets are unknown in fracture healing. While there have been some inroads made into using Notch signaling as a treatment for delayed healing, these studies are in their early stages. The connection between Notch signaling and angiogenesis has been firmly established in cancer and bone tissues, but how this connection affects fracture healing has not been fully investigated. 


\section{Pathological Function of Notch Signaling in Cancer}

Notch signaling plays an essential role in determining the cell-fate decisions and differentiation of the osteoblastic lineage as well as maintaining skeletal homeostasis as described in this review. Therefore, the tight control of Notch activation is required to prevent the development of various malignancies. In particular, aberrant activation of Notch signaling in osteoblastic cells results in the development of a primary malignant bone cancer, osteosarcoma $[98,99]$. Consistent with these results, the expression of Notch signaling components (NOTCH1, NOTCH2, JAG1, and DLL) and downstream genes (HEY1 and HEY2) were highly upregulated in human osteosarcoma cell lines and primary human osteosarcoma samples $[98,100]$. Treatment with $\gamma$-secretase inhibitors in a xenograft mouse model effectively decreases tumor growth $[98,101]$. These findings corroborate the participation of Notch signaling in osteosarcoma pathogenesis. Notch signaling also provokes the initiation of osteosarcoma and facilitates distal organ metastasis. AN osteoblast-specific gain-of-function NICD1 mouse model (Col1a1 2.3kb-Cre; Rosa26 ${ }^{\text {NICD}) ~ d e v e l o p e d ~ s p o n t a n e o u s ~ o s t e o s a r c o m a ~ a n d ~ p u l m o n a r y ~ m e t a s t a s i s ~[99] . ~}$ Furthermore, the progression of osteosarcoma was accelerated in Col1a1 2.3kb-Cre; Rosa2 $6^{\text {NICD }}$ on a p53 null background. Overall, these studies demonstrated a dominant role for Notch signaling in both initiation and progression of osteosarcoma. However, the downstream mechanisms how Notch signaling promotes oncogenesis still needs to be uncovered.

Aberrant genomic integrity, including large structural chromosomal variations, is one of the key characteristics of osteosarcoma. Therefore, genomic instability has been proposed to be a causal factor leading to osteosarcoma. In the NICD transgenic mouse model of osteosarcoma described above, primary osteosarcoma cells revealed cytogenetic complexity including a high rate of aneuploidy as well as recurrent chromosomal abnormalities [99]. This observation indicates that aberrant activation of Notch in osteoblasts could induce the genomic instability found in human osteosarcoma. Previously, Fagagna's group demonstrated a repressive role of Notch signaling in the DNA-damage response (DDR) through the inhibition of ATM signaling [102,103]. ATM signaling is one of the signature DNA damage responses and is recruited to DNA double-stranded breaks when DNA insult occurs. In their study, they showed that Notch1 competes with FOXO3a and KAT5 to form a complex with ATM. This Notch1-ATM complex inhibits ATM activation by blocking the assembly of FOXO3a-KAT5-ATM complex. This study suggested the negative role of Notch signaling in maintaining genomic stability. These collective observations of cytogenetic complexity in primary osteosarcoma and impairment of DDR by aberrant activation of Notch signaling suggest that Notch-induced genomic instability in bone could be one of the downstream mechanisms leading to bone malignancy and pulmonary metastasis. Future efforts are required to decipher the pathological role of Notch signaling in genomic instability and osteosarcoma progression.

Beyond its role in osteosarcoma, Notch signaling has been demonstrated to facilitate bone metastasis. Bone metastasis is one of the major complications of breast and prostate cancer. During the early colonization stage of bone metastasis, disseminated tumor cells reshape the osteogenic niche by establishing pathological cell-cell communication with nearby stromal cells. This niche in return provides proliferation/survival signals to foster outgrowth and hamper therapeutic efficacies [104]. Notch signaling mediates the cell-cell contact between the metastatic tumor cells and bone/stromal cells. In breast cancer, tumor-derived Jag1 induces IL-6 secretion from osteoblasts, which feeds back to cancer cells to promote tumor growth. Meanwhile, the activation of Notch signaling enhances osteoclast maturation and facilitates osteolytic bone metastasis. TGF- $\beta$ released from the destruction of bone matrix also creates a feedback loop to further activate Jag1 expression in tumor cells (termed the "Vicious Cycle") and enhance the metastatic potential of the cancer $[105,106]$. Similarly, in prostate carcinoma, the same mechanisms of osteolytic bone metastasis also enhance metastatic potential via the expression of Notch1 and Jag1 [107,108]. Moreover, the expression of Notch1 is positively correlated with the expression of Epithelial-to-Mesenchymal markers, suggesting a role for Notch signaling in prostate cancer aggressiveness [109]. 
The osteogenic niche also protects metastatic tumor cells from chemotherapy. Zheng et al. discovered a tumor-osteoblast interaction that enhances the chemoresistance of breast cancer. While tumor-derived Jag1 facilitates bone metastasis, chemotherapy induces the expression of Jag1 in osteoblasts and further enhances tumor cell survival [109]. In this study, they showed that Jag1 antibody (15D11) targeting both tumor- and osteoblast-derived Jag1 helps sensitize skeletal metastases to chemotherapy in osteoblastic gain of function Jag1 mouse model.

Together, these studies demonstrated a role of Notch signaling in promoting cancer progression and establishing a bone microenvironment niche for breast cancer bone metastasis. An interesting direction to further explore the role of Notch signaling is its role in angiogenesis, bone niche to sustain cancer cell survival, maintenance of cancer stem cells, and escape of immune surveillance during bone metastasis. Future efforts in understanding Notch-mediated metastasis would also be a fundamental step for developing effective therapies to target Notch-driven cancers and counter osteogenic niche-mediated chemoresistance.

\section{Concluding Remarks}

The endeavor to understand the role of Notch signaling in skeletogenesis and skeletal homeostasis using temporal/spatial deletion and activation of Notch components in mouse models have provided important insights into skeletal conditions such as osteosclerosis, osteoporosis, chondrodysplasia, osteoarthritis and cancers. Importantly, Notch signaling exerts its function in a temporally and spatially dependent manner to maintain the multipotency and proliferation of skeletal progenitors while preventing terminal differentiation, as shown in various skeletal cells, including osteoblast, osteocyte, osteoclast and chondrocyte. Moreover, the dysregulation of Notch signaling has been observed in primary bone cancers and metastatic bone cancers and age-dependent skeletal diseases such as osteoporosis and osteoarthritis. Nevertheless, several human genetic diseases from Notch components clearly demonstrated the significant role of Notch signaling during development and postnatal homeostasis of bone and cartilage. Understanding the roles of signaling sending ligands will help us to develop therapy for skeletal disorders and cancer, although such therapies must likely take into account temporal-spatial restrictions of pathological Notch signaling. Moreover, delineating non-canonical Notch pathway regulators and modifiers will open up a new avenue of therapeutic approach for the treatment of Notch-dependent skeletal disorders.

Funding: This research was funded by National Institutes of Health (NIH) grant and Cancer Prevention Institute of Texas (CPRIT) grant number [RP170488].

Conflicts of Interest: The authors declare no conflict of interest.

\section{References}

1. Stittrich, A.B.; Lehman, A.; Boidan, D.L.; Ashworth, J.; Zong, Z.; Li, H.; Lam, P.; Khromykh, A.; Iyer, R.K.; Vockley, J.G.; et al. Mutations in NOTCH1 cause Adams-Oliver syndrome. Am. J. Hum. Genet. 2014, 95, 275-284. [CrossRef] [PubMed]

2. Hassed, S.J.; Wiley, G.B.; Wang, S.; Lee, J.Y.; Li, S.; Xu, W.; Zhao, Z.J.; Mulvihill, J.J.; Robertson, J.; Warner, J.; et al. RBPJ mutations identified in two families affected by Adams-Oliver syndrome. Am. J. Hum. Genet. 2012, 91, 391-395. [CrossRef] [PubMed]

3. Meester, J.A.; Southgate, L.; Stittrich, A.B.; Vensellar, H.; Beekmans, S.J.; den Hollnader, N.; Bijlsma, E.K.; Helderman-van den Enden, A.; Verheij, J.B.; Glusman, G.; et al. Heterozygous Loss-of-Function Mutations in DLL4 Cause Adams-Oliver Syndrome. Am. J. Hum. Genet. 2015, 97, 475-482. [CrossRef] [PubMed]

4. Emerick, K.M.; Rand, E.B.; Goldmuntz, E.; Krantz, I.D.; Spinner, N.B.; Piccoli, D.A. Features of Alagille syndrome in 92 patients: Frequency and relation to prognosis. Hepatology 1999, 29, 822-829. [CrossRef] [PubMed]

5. $\quad$ Bauer, R.C.; Laney, A.O.; Smith, R.; Gerfen, J.; Morrissette, J.J.; Woyciechowski, S.; Garbarini, J.; Loomes, K.M.; Krantz, I.D.; Urban, Z.; et al. Jagged1 (JAG1) mutations in patients with tetralogy of Fallot or pulmonic stenosis. Hum. Mutat. 2010, 31, 594-601. [CrossRef] 
6. Crosnier, C.; Driancourt, C.; Raynaud, N.; Dhorne-Pollet, S.; Pollet, N.; Bernard, O.; Hadchouel, M.; Meunier-Rotival, M. Mutations in JAGGED1 gene are predominantly sporadic in Alagille syndrome. Gastroenterology 1999, 116, 1141-1148. [CrossRef]

7. Morrissette, J.D.; Colliton, R.P.; Spinner, N.B. Defective intracellular transport and processing of JAG1 missense mutations in Alagille syndrome. Hum. Mol. Genet. 2001, 10, 405-413. [CrossRef]

8. Boyer-Di Ponio, J.; Wright-Crosnier, C.; Groyer-Picard, M.T.; Driancourt, C.; Beau, I.; Hadchouel, M.; Meunier-Rotival, M. Biological function of mutant forms of JAGGED1 proteins in Alagille syndrome: Inhibitory effect on Notch signaling. Hum. Mol. Genet. 2007, 16, 2683-2692. [CrossRef]

9. Kamath, B.M.; Bauer, R.C.; Loomes, K.M.; Chao, G.; Gerfen, J.; Hutchinson, A.; Hardikar, W.; Hirschfield, G.; Jara, P.; Krantz, I.D.; et al. NOTCH2 mutations in Alagille syndrome. J. Med. Genet. 2012, 49, 138-144. [CrossRef]

10. McDaniell, R.; Warthen, D.M.; Sanchez-Lara, P.A.; Pai, A.; Krantz, I.D.; Piccoli, D.A.; Spinner, N.B. $\mathrm{NOTCH} 2$ mutations cause Alagille syndrome, a heterogeneous disorder of the notch signaling pathway. Am. J. Hum. Genet. 2006, 79, 169-173. [CrossRef]

11. Xue, Y.; Gao, X.; Lindsell, C.E.; Norton, C.R.; Chang, B.; Hicks, C.; Gendron-Maguire, M.; Rand, E.B.; Weinmaster, G.; Gridley, T. Embryonic lethality and vascular defects in mice lacking the Notch ligand Jagged1. Hum. Mol. Genet. 1999, 8, 723-730. [CrossRef] [PubMed]

12. McCright, B.; Lozier, J.; Gridley, T. A mouse model of Alagille syndrome: Notch2 as a genetic modifier of Jag1 haploinsufficiency. Development 2002, 129, 1075-1082. [PubMed]

13. Rimoin, D.L.; Fletcher, B.D.; McKusick, V.A. Spondylocostal dysplasia. A dominantly inherited form of short-trunked dwarfism. Am. J. Med. 1968, 45, 948-953. [CrossRef]

14. Turnpenny, P.D.; Whittock, N.; Duncan, J.; Dunwoodie, S.; Kusumi, K.; Ellard, S. Novel mutations in DLL3, a somitogenesis gene encoding a ligand for the Notch signalling pathway, cause a consistent pattern of abnormal vertebral segmentation in spondylocostal dysostosis. J. Med. Genet. 2003, 40, 333-339. [CrossRef]

15. Whittock, N.V.; Sparrow, D.B.; Wouters, M.A.; Sillence, D.; Ellard, S.; Dunwoodie, S.L.; Turnpenny, P.D. Mutated MESP2 causes spondylocostal dysostosis in humans. Am. J. Hum. Genet. 2004, 74, 1249-1254. [CrossRef]

16. Sparrow, D.B.; Guillén-Navarro, E.; Fatkin, D.; Dunwoodie, S.L. Mutation of Hairy-and-Enhancer-of-Split-7 in humans causes spondylocostal dysostosis. Hum. Mol Genet. 2008, 17, 3761-3766. [CrossRef]

17. Sparrow, D.B.; Chapman, G.; Wouters, M.A.; Whittock, N.V.; Ellard, S.; Fatkin, D.; Turnpenny, P.D.; Kusumi, K.; Sillence, D.; Dunwoodie, S.L. Mutation of the LUNATIC FRINGE gene in humans causes spondylocostal dysostosis with a severe vertebral phenotype. Am. J. Hum. Genet. 2006, 78, 28-37. [CrossRef]

18. Bessho, Y.; Sakata, R.; Komatsu, S.; Shiota, K.; Yamada, S.; Kageyama, R. Dynamic expression and essential functions of Hes7 in somite segmentation. Genes. Dev. 2001, 15, 2642-2647. [CrossRef]

19. Okubo, Y.; Sugawara, T.; Abe-Koduka, N.; Kanno, J.; Kimura, A.; Saga, Y. Lfng regulates the synchronized oscillation of the mouse segmentation clock via trans-repression of Notch signalling. Nat. Commun. 2013, 3, 1141. [CrossRef]

20. Sparrow, D.B.; Sillence, D.; Wouters, M.A.; Turnpenny, P.D.; Dunwoodie, S.L. Two novel missense mutations in HAIRY-AND-ENHANCER-OF-SPLIT-7 in a family with spondylocostal dysostosis. Eur. J. Hum. Genet. 2010, 18, 674-679. [CrossRef]

21. Han, M.S.; Ko, J.M.; Cho, T.J.; Park, W.Y.; Cheong, H.I. A novel NOTCH2 mutation identified in a Korean family with Hajdu-Cheney syndrome showing phenotypic diversity. Ann. Clin. Lab. Sci. 2015, 45, 110-114. [PubMed]

22. Majewski, J.; Schwartzentruber, J.A.; Caqueret, A.; Patry, L.; Marcadier, J.; Fryns, J.P.; Boycott, K.M.; Ste-Marie, L.G.; McKiernan, F.E.; Marik, I.; et al. Mutations in NOTCH2 in families with Hajdu-Cheney syndrome. Hum. Mutat. 2011, 32, 1114-1117. [CrossRef] [PubMed]

23. Canalis, E.; Schilling, L.; Yee, S.P.; Lee, S.K.; Zanotti, S. Hajdu Cheney Mouse Mutants Exhibit Osteopenia, Increased Osteoclastogenesis, and Bone Resorption. J. Biol. Chem. 2016, 291, 1538-1551. [CrossRef] [PubMed]

24. Lehman, R.A.; Stears, J.C.; Wesenberg, R.L.; Nusbaum, E.D. Familial osteosclerosis with abnormalities of the nervous system and meninges. J. Pediatr. 1977, 90, 49-54. [CrossRef]

25. Gripp, K.W.; Scott, C.I., Jr.; Hughes, H.E.; Wallerstein, R.; Nicholson, L.; States, L.; Bason, L.D.; Kaplan, P.; Zderic, S.A.; Duhaime, A.C.; et al. Lateral meningocele syndrome: Three new patients and review of the literature. Am. J. Med. Genet. 1997, 70, 229-239. [CrossRef] 
26. Gripp, K.W.; Robbins, K.M.; Sobreira, N.L.; Witmer, P.D.; Bird, L.M.; Avela, K.; Makitie, O.; Alves, D.; Hogue, J.S.; Zackai, E.H.; et al. Truncating mutations in the last exon of NOTCH3 cause lateral meningocele syndrome. Am. J. Med. Genet. A 2015, 167, 271-281. [CrossRef]

27. Andersson, E.R.; Sandberg, R.; Lendahl, U. Notch signaling: Simplicity in design, versatility in function. Development 2011, 138, 3593-3612. [CrossRef]

28. Wuelling, M.; Vortkamp, A. Transcriptional networks controlling chondrocyte proliferation and differentiation during endochondral ossification. Pediatr. Nephrol. 2010, 25, 625-631. [CrossRef]

29. Miraoui, H.; Marie, P.J. Fibroblast growth factor receptor signaling crosstalk in skeletogenesis. Sci. Signal. 2010, 3, 9. [CrossRef]

30. Plaas, A.; Velasco, J.; Gorski, D.J.; Cole, A.; Christopherson, K.; Sandy, J.D. The relationship between fibrogenic TGFbeta1 signaling in the joint and cartilage degradation in post-injury osteoarthritis. Osteoarthr. Cartil. 2011, 19, 1081-1090. [CrossRef]

31. Baldridge, D.; Shchelochkov, O.; Kelley, B.; Lee, B. Signaling pathways in human skeletal dysplasias. Annu. Rev. Genom. Hum. Genet. 2010, 11, 189-217. [CrossRef] [PubMed]

32. Watanabe, N.; Tezuka, Y.; Matsuno, K.; Miyatani, S.; Morimura, N.; Yasuda, M.; Fujimaki, R.; Kuroda, K.; Hiraki, Y.; Hozumi, N.; et al. Suppression of differentiation and proliferation of early chondrogenic cells by Notch. J. Bone Miner. Metab. 2003, 21, 344-352. [CrossRef] [PubMed]

33. Dong, Y.; Jesse, A.M.; Kohn, A.; Gunnell, L.M.; Honjo, T.; Zuscik, M.J.; O’Keefe, R.J.; Hilton, M.J. RBPjkappa-dependent Notch signaling regulates mesenchymal progenitor cell proliferation and differentiation during skeletal development. Development 2010, 137, 1461-1471. [CrossRef] [PubMed]

34. Fujimaki, R.; Toyama, Y.; Hozumi, N.; Tezuka, K. Involvement of Notch signaling in initiation of prechondrogenic condensation and nodule formation in limb bud micromass cultures. J. Bone Miner. Metab. 2006, 24, 191-198. [CrossRef] [PubMed]

35. Grogan, S.P.; Olee, T.; Hiraoka, K.; Lotz, M.K. Repression of chondrogenesis through binding of notch signaling proteins HES-1 and HEY-1 to N-box domains in the COL2A1 enhancer site. Arthritis Rheum. 2008, 58, 2754-2763. [CrossRef]

36. Mead, T.J.; Yutzey, K.E. Notch pathway regulation of chondrocyte differentiation and proliferation during appendicular and axial skeleton development. Proc. Natl. Acad. Sci. USA 2009, 106, 14420-14425. [CrossRef]

37. Crowe, R.; Zikherman, J.; Niswander, L. Delta-1 negatively regulates the transition from prehypertrophic to hypertrophic chondrocytes during cartilage formation. Development 1999, 126, 987-998.

38. Rutkowski, T.P.; Kohn, A.; Sharma, D.; Ren, Y.; Mirando, A.J.; Hilton, M.J. HES factors regulate specific aspects of chondrogenesis and chondrocyte hypertrophy during cartilage development. J. Cell Sci. 2016, 129, 2145-2155. [CrossRef]

39. Karlsson, C.; Brantsing, C.; Kageyama, R.; Lindahl, A. HES1 and HES5 are dispensable for cartilage and endochondral bone formation. Cells Tissues Organs. 2010, 192, 17-27. [CrossRef]

40. Tian, Y.; Xu, Y.; Fu, Q.; Chang, M.; Wang, Y.; Shang, X.; Wan, C.; Marymont, J.V.; Dong, Y. Notch inhibits chondrogenic differentiation of mesenchymal progenitor cells by targeting Twist1. Mol. Cell Endocrinol. 2015, 403, 30-38. [CrossRef]

41. Hilton, M.J.; Tu, X.; Wu, X.; Bai, S.; Zhao, H.; Kobayashi, T.; Kronenberg, H.M.; Teitelbaum, S.L.; Ross, F.P.; Kopan, R.; et al. Notch signaling maintains bone marrow mesenchymal progenitors by suppressing osteoblast differentiation. Nat. Med. 2008, 14, 306-314. [CrossRef] [PubMed]

42. Tu, X.; Chen, J.; Lim, J.; Karner, C.M.; Lee, S.Y.; Heisig, J.; Wiese, C.; Surendran, K.; Kopan, R.; Gessler, M.; et al. Physiological notch signaling maintains bone homeostasis via RBPjk and Hey upstream of NFATc1. PLoS Genet. 2018, 8, e1002577. [CrossRef] [PubMed]

43. Zhao, Q.; Eberspaecher, H.; Lefebvre, V.; De Crombrugghe, B. Parallel expression of Sox9 and Col2a1 in cells undergoing chondrogenesis. Dev. Dyn. 1997, 209, 377-386. [CrossRef]

44. Chen, S.; Tao, J.; Bae, Y.; Jiang, M.M.; Bertin, T.; Chen, Y.; Yang, T.; Lee, B. Notch gain of function inhibits chondrocyte differentiation via Rbpj-dependent suppression of Sox9. J. Bone Miner. Res. 2013, 28, 649-659. [CrossRef]

45. Dahlqvist, C.; Blokzijl, A.; Chapman, G.; Falk, A.; Dannaeus, K.; Ibâñez, C.F.; Lendahl, U. Functional Notch signaling is required for BMP4-induced inhibition of myogenic differentiation. Development 2003, 130, 6089-6099. [CrossRef] 
46. Itoh, F.; Itoh, S.; Goumans, M.J.; Valdimarsdottir, G.; Iso, T.; Dotto, G.P.; Hamamori, Y.; Kedes, L.; Kato, M.; ten Dijke, P. Synergy and antagonism between Notch and BMP receptor signaling pathways in endothelial cells. EMBO J. 2004, 23, 541-551. [CrossRef]

47. Blokzijl, A.; Dahlqvist, C.; Reissmann, E.; Falk, A.; Moliner, A.; Lendahl, U.; Ibáñez, C.F. Cross-talk between the Notch and TGF-beta signaling pathways mediated by interaction of the Notch intracellular domain with Smad3. J. Cell Biol. 2003, 163, 723-728. [CrossRef]

48. Ross, D.A.; Kadesch, T. The notch intracellular domain can function as a coactivator for LEF-1. Mol. Cell Biol. 2001, 21, 7537-7544. [CrossRef]

49. Axelrod, J.D.; Matsuno, K.; Artavanis-Tsakonas, S.; Perrimon, N. Interaction between Wingless and Notch signaling pathways mediated by dishevelled. Science 1996, 271, 1826-1832. [CrossRef]

50. Hayward, P.; Brennan, K.; Sanders, P.; Balayo, T.; DasGupta, R.; Perrimon, N.; Arias, A.M. Notch modulates Wnt signalling by associating with Armadillo/beta-catenin and regulating its transcriptional activity. Development 2005, 132, 1819-1830. [CrossRef]

51. Vacca, A.; Felli, M.P.; Palermo, R.; Di Mario, G.; Calce, A.; Di Giovine, M.; Frati, L.; Gulino, A.; Screpanti, I. Notch3 and pre-TCR interaction unveils distinct NF-kappaB pathways in T-cell development and leukemia. EMBO J. 2006, 25, 1000-1008. [CrossRef] [PubMed]

52. Vilimas, T.; Mascarenhas, J.; Palomero, T.; Mandal, M.; Buonamici, S.; Meng, F.; Thompson, B.; Spaulding, C.; Macaroun, S.; Alegre, M.L. Targeting the NF-kappaB signaling pathway in Notch1-induced T-cell leukemia. Nat. Med. 2007, 13, 70-77. [CrossRef] [PubMed]

53. Wang, J.; Shelly, L.; Miele, L.; Boykins, R.; Norcross, M.A.; Guan, E. Human Notch-1 inhibits NF-kappa B activity in the nucleus through a direct interaction involving a novel domain. J. Immunol. 2001, 167, 289-295. [CrossRef] [PubMed]

54. Kohn, A.; Dong, Y.; Mirando, A.J.; Jesse, A.M.; Honjo, T.; Zuscik, M.J.; O’Keefe, R.J.; Hilton, M.J. Cartilage-specific RBPjkappa-dependent and -independent Notch signals regulate cartilage and bone development. Development 2012, 139, 1198-1212. [CrossRef] [PubMed]

55. Kronenberg, H.M. Developmental regulation of the growth plate. Nature 2003, 423, 332-336. [CrossRef] [PubMed]

56. Goldring, M.B.; Goldring, S.R. Osteoarthritis. J. Cell Physiol. 2007, 213, 626-634. [CrossRef]

57. Goldring, M.B.; Marcu, K.B. Cartilage homeostasis in health and rheumatic diseases. Arthritis Res. Ther. 2009, 11, 224. [CrossRef]

58. Pacifici, M.; Koyama, E.; Iwamoto, M. Mechanisms of synovial joint and articular cartilage formation: Recent advances, but many lingering mysteries. Birth Defects Res. C Embryo Today 2005, 75, 237-248. [CrossRef]

59. Sandell, L.J. Etiology of osteoarthritis: Genetics and synovial joint development. Nat. Rev. Rheumatol. 2012, 8, 77-89. [CrossRef]

60. Karlsson, C.; Jonsson, M.; Asp, J.; Brantsing, C.; Kageyama, R.; Lindahl, A. Notch and HES5 are regulated during human cartilage differentiation. Cell Tissue Res. 2007, 327, 539-551. [CrossRef]

61. Ustunel, I.; Ozenci, A.M.; Sahin, Z.; Ozbey, O.; Acar, N.; Tanriover, G.; Celik-Ozenci, C.; Demir, R. The immunohistochemical localization of notch receptors and ligands in human articular cartilage, chondroprogenitor culture and ultrastructural characteristics of these progenitor cells. Acta Histochem. 2008, 110, 397-407. [CrossRef] [PubMed]

62. Karlsson, C.; Brantsing, C.; Egell, S.; Lindahl, A. Notch1, Jagged1, and HES5 are abundantly expressed in osteoarthritis. Cells Tissues Organs. 2008, 188, 287-298. [CrossRef] [PubMed]

63. Liu, Z.; Chen, J.; Mirando, A.J.; Wang, C.; Zuscik, M.J.; O'Keefe, R.J.; Hilton, M.J. A dual role for NOTCH signaling in joint cartilage maintenance and osteoarthritis. Sci. Signal 2015, 8, ra71. [CrossRef] [PubMed]

64. Hosaka, Y.; Saito, T.; Sugita, S.; Hikata, T.; Kobayashi, H.; Fukai, A.; Taniguchi, Y.; Hirata, M.; Akiyama, H.; Chung, U.I.; et al. Notch signaling in chondrocytes modulates endochondral ossification and osteoarthritis development. Proc. Natl. Acad. Sci. USA 2013, 110, 1875-1880. [CrossRef]

65. Mirando, A.J.; Liu, Z.; Moore, T.; Lang, A.; Kohn, A.; Osinski, A.M.; O’Keefe, R.J.; Mooney, R.A.; Zuscik, M.J.; Hilton, M.J. RBP-Jkappa-dependent Notch signaling is required for murine articular cartilage and joint maintenance. Arthritis Rheum. 2013, 65, 2623-2633.

66. Canalis, E.; Parker, K.; Feng, J.Q.; Zanotti, S. Osteoblast lineage-specific effects of notch activation in the skeleton. Endocrinology 2013, 154, 623-634. [CrossRef] 
67. Zanotti, S.; Smerdel-Ramoya, A.; Stadmeyer, L.; Durant, D.; Radtke, F.; Canalis, E. Notch inhibits osteoblast differentiation and causes osteopenia. Endocrinology 2008, 149, 3890-3899. [CrossRef]

68. Lawal, R.A.; Zhou, X.; Batey, K.; Hoffman, C.M.; Georger, M.A.; Radtke, F.; Hilton, M.J.; Xing, L.; Frisch, B.J.; Calvi, L.M. The Notch Ligand Jagged1 Regulates the Osteoblastic Lineage by Maintaining the Osteoprogenitor Pool. J. Bone Miner. Res. 2017, 32, 1320-1331. [CrossRef]

69. Muguruma, Y.; Hozumi, K.; Warita, H.; Yahata, T.; Uno, T.; Ito, M.; Ando, K. Maintenance of Bone Homeostasis by DLL1-Mediated Notch Signaling. J. Cell Physiol. 2017, 232, 2569-2580. [CrossRef]

70. Engin, F.; Yao, Z.; Yang, T.; Zhou, G.; Bertin, T.; Jiang, M.M.; Chen, Y.; Wang, L.; Zheng, H.; Sutton, R.E.; et al. Dimorphic effects of Notch signaling in bone homeostasis. Nat Med 2008, 14, 299-305. [CrossRef]

71. Canalis, E.; Adams, D.J.; Boskey, A.; Parker, K.; Kranz, L.; Zanotti, S. Notch signaling in osteocytes differentially regulates cancellous and cortical bone remodeling. J. Biol. Chem. 2013, 288, 25614-25625. [CrossRef] [PubMed]

72. Canalis, E.; Bridgewater, D.; Schilling, L.; Zanotti, S. Canonical Notch activation in osteocytes causes osteopetrosis. Am. J. Physiol. Endocrinol. Metab. 2016, 310, E171-E182. [CrossRef] [PubMed]

73. Tao, J.; Chen, S.; Lee, B. Alteration of Notch signaling in skeletal development and disease. Ann. N. Y. Acad. Sci. 2010, 1192, 257-268. [CrossRef] [PubMed]

74. Engin, F.; Lee, B. NOTCHing the bone: Insights into multi-functionality. Bone 2010, 46, 274-280. [CrossRef]

75. Barak, H.; Surendran, K.; Boyle, S.C. The role of Notch signaling in kidney development and disease. Adv. Exp. Med. Biol. 2017, 727, 99-113.

76. Chen, S.; Lee, B.H.; Bae, Y. Notch signaling in skeletal stem cells. Calcif. Tissue Int. 2014, 94, 68-77. [CrossRef]

77. Canalis, E. Notch in skeletal physiology and disease. Osteoporos. Int 2018, 29, 2611-2621. [CrossRef]

78. Lee, S.Y.; Long, F. Notch signaling suppresses glucose metabolism in mesenchymal progenitors to restrict osteoblast differentiation. J. Clin. Invest. 2018, 128, 5573-5586. [CrossRef]

79. Ziouti, F.; Ebert, R.; Rummler, M.; Krug, M.; Müller-Deubert, S.; Lüdemann, M.; Jakob, F.; Willie, B.M.; Jundt, F. NOTCH Signaling Is Activated through Mechanical Strain in Human Bone Marrow-Derived Mesenchymal Stromal Cells. Stem. Cells Int. 2019, 2019, 5150634. [CrossRef]

80. Simonet, W.S.; Lacey, D.L.; Dunstan, C.R.; Kelley, M.; Chang, M.S.; Lüthy, R.; Nguyen, H.Q.; Wooden, S.; Bennett, L.; Boone, T.; et al. Osteoprotegerin: A novel secreted protein involved in the regulation of bone density. Cell 1997, 89, 309-319. [CrossRef]

81. Sekine, C.; Koyanagi, A.; Koyama, N.; Hozumi, K.; Chiba, S.; Yagita, H. Differential regulation of osteoclastogenesis by Notch2/Delta-like 1 and Notch1/Jagged1 axes. Arthritis Res. Ther. 2012, 14, R45. [CrossRef]

82. Yamada, T.; Yamazaki, H.; Yamane, T.; Yoshino, M.; Okuyama, H.; Tsuneto, M.; Kurino, T.; Hayashi, S.; Sakano, S. Regulation of osteoclast development by Notch signaling directed to osteoclast precursors and through stromal cells. Blood 2003, 101, 2227-2234. [CrossRef]

83. Fukushima, H.; Nakao, A.; Okamoto, F.; Shin, M.; Kajiya, H.; Sakano, S.; Bigas, A.; Jimi, E.; Okabe, K. The association of Notch2 and NF-kappaB accelerates RANKL-induced osteoclastogenesis. Mol. Cell Biol. 2008, 28, 6402-6412. [CrossRef]

84. Bai, S.; Kopan, R.; Zou, W.; Hilton, M.J.; Ong, C.T.; Long, F.; Ross, F.P.; Teitelbaum, S.L. NOTCH1 regulates osteoclastogenesis directly in osteoclast precursors and indirectly via osteoblast lineage cells. J. Biol. Chem. 2008, 283, 6509-6518. [CrossRef]

85. Ashley, J.W.; Ahn, J.; Hankenson, K.D. Notch signaling promotes osteoclast maturation and resorptive activity. J. Cell Biochem. 2015, 116, 2598-2609. [CrossRef]

86. Zhao, B.; Grimes, S.N.; Li, S.; Hu, X.; Ivashkiv, L.B. TNF-induced osteoclastogenesis and inflammatory bone resorption are inhibited by transcription factor RBP-J. J. Exp. Med. 2012, 209, 319-334. [CrossRef]

87. Zanotti, S.; Smerdel-Ramoya, A.; Canalis, E. HES1 (hairy and enhancer of split 1) is a determinant of bone mass. J. Biol. Chem. 2010, 286, 2648-2657. [CrossRef]

88. Zanotti, S.; Yu, J.; Sanjay, A.; Shilling, L.; Schoenherr, C.; Economides, A.N.; Canalis, E. Sustained Notch2 signaling in osteoblasts, but not in osteoclasts, is linked to osteopenia in a mouse model of Hajdu-Cheney syndrome. J. Biol. Chem. 2017, 292, 12232-12244. [CrossRef]

89. Dishowitz, M.I.; Terkhorn, S.P.; Bostic, S.A.; Hankenson, K.D. Notch signaling components are upregulated during both endochondral and intramembranous bone regeneration. J. Orthop. Res. 2013, 30, $296-303$. [CrossRef] 
90. Dishowitz, M.I.; Mutyaba, P.L.; Takacs, J.D.; Barr, A.M.; Engiles, J.B.; Ahn, J.; Hankenson, K.D. Systemic inhibition of canonical Notch signaling results in sustained callus inflammation and alters multiple phases of fracture healing. PLoS ONE 2013, 8, e68726. [CrossRef]

91. Wang, C.; Inzana, J.A.; Mirando, A.J.; Ren, Y.; Liu, Z.; Shen, J.; O’Keefe, R.J.; Awad, H.A.; Hilton, M.J. NOTCH signaling in skeletal progenitors is critical for fracture repair. J. Clin. Invest. 2016, 126, 1471-1481. [CrossRef]

92. Matthews, B.G.; Grcevic, D.; Wang, L.; Hagiwara, Y.; Roguljic, H.; Joshi, P.; Shin, D.G.; Adams, D.J.; Kalajzic, I. Analysis of alphaSMA-labeled progenitor cell commitment identifies notch signaling as an important pathway in fracture healing. J. Bone Miner. Res. 2014, 29, 1283-1294. [CrossRef]

93. Tian, Y.; Xu, Y.; Xue, T.; Chen, L.; Shi, B.; Shu, B.; Xie, C.; Max Morandi, M.; Jaeblon, T.; Marymount, J.V.; et al. Notch activation enhances mesenchymal stem cell sheet osteogenic potential by inhibition of cellular senescence. Cell Death Dis. 2017, 8, e2595. [CrossRef]

94. Youngstrom, D.W.; Senos, R.; Zondervan, R.L.; Brodeur, J.D.; Lints, A.R.; Young, D.R.; Mitchell, T.L.; Moore, M.E.; Myers, M.H.; Tseng, W.J.; et al. Intraoperative delivery of the Notch ligand Jagged-1 regenerates appendicular and craniofacial bone defects. NPJ Regen. Med. 2017, 2, 32. [CrossRef]

95. Ramasamy, S.K.; Kusumbe, A.P.; Wang, L.; Adams, R.H. Endothelial Notch activity promotes angiogenesis and osteogenesis in bone. Nature 2014, 507, 376-380. [CrossRef]

96. Benedito, R.; Hellstrom, M. Notch as a hub for signaling in angiogenesis. Exp Cell Res. 2013, 319, 1281-1288. [CrossRef]

97. Hausman, M.R.; Schaffler, M.B.; Majeska, R.J. Prevention of fracture healing in rats by an inhibitor of angiogenesis. Bone 2001, 29, 560-564. [CrossRef]

98. Engin, F.; Bertin, T.; Ma, O.; Jiang, M.M.; Wang, L.; Sutton, R.E.; Donehower, L.A.; Lee, B. Notch signaling contributes to the pathogenesis of human osteosarcomas. Hum. Mol. Genet. 2009, 18, 1464-1470. [CrossRef]

99. Tao, J.; Jiang, M.M.; Jiang, L.; Salvo, J.S.; Zeng, H.C.; Dawson, B.; Bertin, T.K.; Rao, P.H.; Chen, R.; Donehower, L.A.; et al. Notch activation as a driver of osteogenic sarcoma. Cancer Cell 2014, 26, 390-401. [CrossRef]

100. Hughes, D.P. How the NOTCH pathway contributes to the ability of osteosarcoma cells to metastasize. Cancer Treat. Res. 2009, 152, 479-496.

101. Tanaka, M.; Setoguchi, T.; Hirotsu, M.; Gao, H.; Sasaki, H.; Matsunoshita, Y.; Komiya, S. Inhibition of Notch pathway prevents osteosarcoma growth by cell cycle regulation. Br. J. Cancer 2009, 100, 1957-1965. [CrossRef]

102. Vermezovic, J.; Adamowicz, M.; Santarpia, L.; Rustighi, A.; Forcato, M.; Lucano, C.; Massimiliano, L.; Costanzo, V.; Bicciato, S.; Del Sal, G.; et al. Notch is a direct negative regulator of the DNA-damage response. Nat. Struct. Mol. Biol. 2015, 22, 417-424. [CrossRef]

103. Adamowicz, M.; Vermezovic, J.; di Fagagna, F.D. NOTCH1 Inhibits Activation of ATM by Impairing the Formation of an ATM-FOXO3a-KAT5/Tip60 Complex. Cell Rep. 2016, 6, 2068-2076. [CrossRef]

104. Wang, H.; Yu, C.; Gao, X.; Welte, T.; Muscarella, A.M.; Tian, L.; Zhao, H.; Zhao, Z.; Du, S.; Tao, J.; et al. The osteogenic niche promotes early-stage bone colonization of disseminated breast cancer cells. Cancer Cell 2018, 27, 193-210. [CrossRef]

105. Cappariello, A.; Loftus, A.; Muraca, M.; Maurizi, A.; Rucci, N.; Teti, A. Osteoblast-Derived Extracellular Vesicles Are Biological Tools for the Delivery of Active Molecules to Bone. J. Bone Miner. Res. 2018, 33, 517-533. [CrossRef]

106. Cook, L.M.; Shay, G.; Araujo, A.; Lynch, C.C. Integrating new discoveries into the "vicious cycle" paradigm of prostate to bone metastases. Cancer Metastasis Rev. 2015, 33, 511-525. [CrossRef]

107. Santagata, S.; Demichelis, F.; Riva, A.; Varambally, S.; Hofer, M.D.; Kutok, J.L.; Kim, R.; Tang, J.; Montie, J.E.; Chinnaiyan, A.M.; et al. JAGGED1 expression is associated with prostate cancer metastasis and recurrence. Cancer Res. 2004, 64, 6854-6857. [CrossRef]

108. Zayzafoon, M.; Abdulkadir, S.A.; McDonald, J.M. Notch signaling and ERK activation are important for the osteomimetic properties of prostate cancer bone metastatic cell lines. J. Biol. Chem. 2004, 279, 3662-3670. [CrossRef]

109. Zheng, H.; Bae, Y.; Kasimir-Bauer, S.; Tang, R.; Chen, J.; Ren, G.; Yuan, M.; Esposito, M.; Li, W.; Wei, Y.; et al. Therapeutic Antibody Targeting Tumor- and Osteoblastic Niche-Derived Jagged1 Sensitizes Bone Metastasis to Chemotherapy. Cancer Cell 2017, 32, 731-747. [CrossRef]

(C) 2020 by the authors. Licensee MDPI, Basel, Switzerland. This article is an open access article distributed under the terms and conditions of the Creative Commons Attribution (CC BY) license (http://creativecommons.org/licenses/by/4.0/). 